\title{
General Intelligence and the Dark Triad
}

\author{
A Meta-Analysis
}

\author{
Moritz Michels
}

Institute of Psychology, University of Wuppertal, Germany

\begin{abstract}
The dark triad of personality (D3) - consisting of psychopathy, Machiavellianism, and narcissism - is a set of socially aversive personality traits. All three traits encompass disagreeable behavior and a particular disregard for the well-being of others, but also a tendency to strategic and deceptive manipulation of social environments in order to attain one's goals. To exercise these complex manipulations effectively it seems beneficial to have high cognitive abilities. Therefore, a meta-analysis was conducted to examine possible relationships between intelligence and the dark triad. A total of 143 studies were identified to estimate the strength of relationships between the D3 and general, verbal, and nonverbal intelligence. The results indicate that none of the constructs of the dark triad are meaningfully related to intelligence. However, there was a small negative correlation between intelligence and Factor 2 psychopathy. The substantial heterogeneity regarding the observed effect sizes could not be explained with meta-regression for the most part. There was no evidence for a publication bias. In total, the results challenge the notion that the dark triad is an adaptive set of personality traits that enables individuals to effectively manipulate their social surroundings.
\end{abstract}

Keywords: intelligence, psychopathy, Machiavellianism, narcissism, meta-analysis

Since Paulhus and Williams (2002) grouped three psychological constructs - psychopathy, Machiavellianism, and narcissism - into an infamous conglomerate, the so-called dark triad of personality (D3) has become a prominent model to describe, explain and predict socially aversive behavior. Psychopathy (P) is characterized by superficial charm, deceptive and manipulating behavior, a lack of remorse, empathy, and emotionality, a tendency to criminality, as well as antisocial behavior in general (Hare, 1999). Machiavellianism (M) describes a lack of effect in interpersonal relations, a utilitarian worldview with no firm moral standards, a tendency to manipulate others, and a lack of psychopathology (Christie \& Geis, 1970). Narcissistic (N) individuals tend to feel superior to others, brag about themselves, and intend to dominate their social environment (Raskin \& Hall, 1981).

On a conceptual level, the constructs of the D3 share several features, like low interpersonal effect, a tendency of manipulation, the need to dominate others, or a general tendency of indifference to the interests of others. This impedes a conceptual differentiation between the $\mathrm{P}, \mathrm{M}$, and $\mathrm{N}$, which is also reflected in its operationalizations. Consequently, the triad shows high empirical overlap (Muris et al., 2017; Vize et al., 2018). Yet, some conceptual features of the dark triad are at odds with one another, for example, in regards to the role of impulsivity for $\mathrm{M}$ and $\mathrm{P}$ (Furnham et al., 2013; Jones \& Paulhus, 2011; McHoskey et al., 1998).
Recently, the dark triad has been expanded by the inclusion of everyday sadism to be described as the "dark tetrad" (Paulhus, 2014), but is also faced with theoretical "competition" due to the emergence of the Honesty-Humility-factor $(\mathrm{HH})$ from the HEXACO-model by Lee and Ashton (2013). There is convincing empirical evidence that (low) $\mathrm{HH}$ is the "core" of the D3 and is best suited to explain the common D3-variance (Hodson et al., 2018). Moshagen et al. (2018) demonstrated that "D" - the so-called dark factor of personality that partly consists of shared D3-variance has a strong empirical overlap with low HH. A strong negative correlation regarding D3 and agreeableness has also been reported (O'Boyle et al., 2015) which makes (dis-) agreeableness another valid candidate for the D3-core.

Several authors have argued that the D3 is an adaptive set of personality traits that enable D3-individuals to manipulate their social surroundings effectively: Psychopaths are thought to be "smooth operators" and exploitative social predators that are able to reach powerful positions as managers or politicians (Babiak \& Hare, 2006; Babiak et al., 2010; Furnham, 2010; Hare, 1999; Porter et al., 2009), Machiavellians are seen as a cold manipulator with complex plans to achieve their objectives (Bereczkei, 2018; Christie \& Geis, 1970; Simonton, 1986; Wilson et al., 1998) and narcissist are claimed to be charming entertainers (Back et al., 2010; Jauk et al., 2016; Jonason et al., 2012; Paulhus, 1998). 


\section{The Dark Triad and Intelligence}

It is not uncommon among D3-researchers to assume that the tendency to show manipulative behavior goes along with the actual ability to manipulate others effectively (Jonason \& Webster, 2012; Nagler et al., 2014). Although the empirical support for this claim is sparse and some authors have recently challenged this view of highly adaptive D3-individuals (Jones \& Paulhus, 2009; Lilienfeld et al., 2015; Watts et al., 2013; Wright et al., 2015), it does not seem implausible at first. Consequently, one might deduce that either (a) certain theoretical aspects of the dark triad lead to successful manipulations or (b) that the D3 are then again positively related to other variables that are commonly connected to criteria of success. If one follows the logic of the latter aspect, intelligence seems to be a valid candidate for examination, since it has been shown to be a relevant predictor of several criteria of success (Schmidt \& Hunter, 1998; Sternberg, 1997; Strenze, 2007). Additionally, it seems conceptionally plausible that complex manipulative behavior is more likely to be successful if the manipulator has high cognitive abilities. One might even argue that D3-individuals actually "need" a certain level of intelligence to conduct their socially aversive behavior in an effective manner (Salekin et al., 2004). This might especially apply to social intelligence and emotional intelligence which can be conceived as sub-branches of intelligence (Conzelmann et al., 2013; Mayer et al., 2016). Currently, there is almost no empirical evidence on the D3-relations regarding social intelligence, but there have been metaanalyses on the dark triad and emotional intelligence (Megías et al., 2018; Miao et al., 2019; Vize et al., 2018).

In this study, a possible relation between the dark triad of personality and cognitive ability was examined in order to further inspect if D3-individuals are able to function normally and if they are predisposed for (mal-)adaptive behavior due to their (low) intelligence. The method of choice was a systematic literature review in combination with a meta-analysis. In this study, the primary issue was the D3-relation with general intelligence. The D3-relations with potential sub-branches of intelligence were examined: verbal (to examine if D3-individuals might have superior verbal abilities that might support their manipulation tactics specifically in social situations) and non-verbal intelligence (to examine if D3-individuals might have special abstract abilities that might enable them to generate complex manipulative plans in advance).

\section{Theory-Based Expectations}

For $\mathrm{M}$ and $\mathrm{P}$, there are a few theoretical/conceptual allusions that might constitute a relationship with intelligence. In the course of the first psychopathy concept, Cleckley (1941) describes the psychopath as an individual with "good 'intelligence'," although he mostly refers to psychopathic pseudo-intellectuality rather than actual high cognitive abilities. Most studies with the P-intelligence-relation as their main topic refer to Checkley's casuistic reports (Johansson \& Kerr, 2005; Salekin et al., 2004; Sharratt et al., 2019; Vitacco et al., 2008) as the reason to examine this relationship: Some individuals have shown psychopathic behavior and had high intelligence at the same time. Studies on cognitive features of psychopathy seem to suggest that there are very specific deficits or abnormalities in bottom-up and hemispheric processing (Hiatt \& Newman, 2006) with no relation to general intelligence, but rather emotional deficits and impulsivity (Fowles \& Dindo, 2006). Criminal behavior has been linked to lower intelligence (Bartels et al., 2010; Gendreau et al., 1996) and since one crucial aspect of (secondary) psychopathy is a history of criminality, it might constitute a negative empirical connection between intelligence and P. Vitacco et al. (2008) expect no overall effect for intelligence and $\mathrm{P}$, but presume that there might be different relations on the P-facet-level to intelligence (positive relations to primary $\mathrm{P}$ and negative relations to secondary P). The concept of "Machiavellian Intelligence" suggests that Machiavellians possess special cognitive abilities - although the term is originally used in evolutionary psychology and not personality/social psychology (Whiten \& Byrne, 1997). Nevertheless, Bereczkei (2018) refers to the concept and argues that Machiavellians do have certain cognitive abilities that enable them to effectively exploit others. One might consider Machiavellian behavior as "smart" since it (conceptionally) relies on careful planning and complex manipulations, but note that the attempt to act in a complex way is not necessarily related to that specific ability. Furthermore, there is no convincing evidence that high-scorers on existing M-tests behave in a "Machiavellian," that is, carefully planned manner. Although narcissists themselves claim to have high cognitive abilities, they have shown to overstate their intelligence more than others (Gabriel et al., 1994). Zajenkowski and Dufner (2020) state that self-perceived (high) intelligence plays a key role in narcissistic self-views: Narcissists attribute their successes to their (assumed) high intelligence and are eager to appear as intelligent individuals to others - although narcissism was unrelated to performance in IQ-tests. Nevertheless, it might be possible that individuals with high intelligence might "acquire" a form of narcissism as a consequence of their various successes in life which would result in a positive link between narcissism and intelligence. Beyond that, there is no theoretical reason to assume that there is a relationship between $\mathrm{N}$ and intelligence. Note that no D3-model specifically includes or mentions any relation to intelligence. Finally, there was no reason to expect that the D3-traits might be related to sub-branches of intelligence distinctively, for example, 
$\mathrm{M}$ being related to verbal intelligence, but not non-verbal intelligence. Taken together, no relations between the dark triad and general intelligence can be expected based on their concepts.

\section{Empirically-Based Expectations}

Apart from the aforementioned conceptional examination, note that work by Mischel (1968) already demonstrated that personality is at most moderately related to external criteria - consequently, meaningful relations seem unlikely in the first place. Various studies have shown that cognitive ability is often weakly related to personality. This has been shown for the Five-Factor-Model of personality (Ackerman \& Heggestad, 1997; Furnham et al., 2005), but also the HEXACO-model (Oh et al., 2014). Especially the latter finding is notable for this study: Since low HonestyHumility seems to be the empirical (not theoretical) core of the dark triad and $\mathrm{HH}$ is unrelated to cognitive ability, it appears unlikely that there is an empirical connection between intelligence and the dark triad. Furthermore, there are already two meta-analyses on the D3-intelligence relation that find a small negative effect for psychopathy and intelligence (de Ribera et al., 2017) and no relation at all for the complete triad (O'Boyle et al., 2013). Both analyses either rely on D3-self-reports or include D3-tests that have not shown to be valid operationalizations. The metaanalysis by de Ribera et al. (2017) included effect sizes for psychopathy that might not be suited for aggregation due to heterogeneous psychopath-vs.-nonpsychopath-comparisons. The meta-analysis by O'Boyle et al. (2013) had a comparably small study sample. Consequently, it seemed reasonable to conduct a new meta-analysis.

\section{Hypotheses}

Taken together, there are only weak conceptual and empirical arguments that might feed the expectation of a meaningful D3-intelligence-relation. Based on the theoretical relationships between the constructs as well as the available empirical evidence referred to in the previous sections, it was hypothesized that (a) there is no relation between psychopathy and general, verbal, and non-verbal intelligence. Furthermore, the author expected (b) Machiavellianism and (c) narcissism each to be unrelated to general, verbal, and non-verbal intelligence. The hypotheses were not preregistered.

Several authors show that the D3 is related to relevant criteria of success in a non-linear way and argue that there might be an optimal level of D3-constructs (Grijalva et al., 2015; Leary \& Ashman, 2018; Zettler \& Solga, 2013). In an exploratory analysis, it was additionally tested if there are meaningful non-linear relations with $\mathrm{P}$ and intelligence. To test for these relations it was necessary to analyze raw data from the studies.

\section{Method}

\section{Literature Search and Study Selection Inclusion Criteria}

The systematic literature search was conducted in July 2017 and ended in April 2019. The databases PsycINFO, PsycARTICLES, Psyndex, Medline, Psychology, and Behavioral Sciences Collection and ISI - Web of Knowledge were searched by using the following terms and their combinations ("dark triad" OR psychopathy OR psychopath OR psychopathic OR sociopath* OR narcissist ${ }^{*}$ OR Machiavellian*) and (intelligent ${ }^{*}$ OR "cognitive ability" OR "cognitive skill*" OR "mental ability" OR "cognitive competence*") to retrieve publications written in English ("dark triad" OR psychopathy OR psychopath OR psychopathic* OR sociopath $^{*}$ OR narcissist ${ }^{*}$ OR Machiavelli*) and (Intelligen ${ }^{*}$ OR "Kognitive Fähigkeit"* OR "Kognitive Kompetenz") for publications in German. In addition to searching the databases, reference lists of pertinent articles and the two recent meta-analyses by De Ribera et al. (2017) and O'Boyle et al. (2013) were inspected in order to identify additional relevant publications. Figure 1 shows a PRISMA flow diagram (Moher et al., 2009) documenting the literature search results.

The total number of potentially relevant publications identified through the full-text search for screening was 9636 (set B). Since the author was unable to properly assess such a high number of studies, a subset of B - the set A - was identified by using a regular search strategy (no full-text search; only title, keywords, and abstracts were considered; $n=1,446)$. Five hundred studies with a DOInumber and 100 studies without a DOI-number were randomly selected from the complement of A $(n=8,190)$ to check if the complement embodied a substantial amount of relevant studies. Only 3 studies were relevant. Consequently, the remaining studies from the complement of A were not screened for relevance. The studies from set A were screened for relevance and 301 studies were identified as potentially relevant. After the exclusion of duplicates and the inclusion of studies from additional sources that were not embodied in Set B $(n=43$ studies from the meta-analyses, $n=5$ identified by chance) and the 3 studies from the complement of A, 302 full-text articles were assessed for eligibility.

To be included in the meta-analysis, studies had to provide sufficient information for effect size and the associated 
standard error that indicated the strength of association between at least one of the D3-constructs and general, verbal, or nonverbal intelligence. Furthermore, to ensure a minimum psychometric quality of the instruments used in the included studies, the reliability of both instruments used to estimate the strength of the association had to reach a level of at least .60. Most of the studies provided Pearson correlations as effect sizes. Nevertheless, it is common that psychopathy is dichotomized: a "psychopathgroup" is often compared with a "non-psychopath-group." To be included these particular studies had to fulfill a few conditions that were derived from the Psychopathy-Checklist-Revised-Manual (PCL/PCL-R; Hare, 2003): These studies were eligible if (a) a PCL-R-Cut-Off of 30 points was used for the psychopath-group, (b) the non-psychopathgroup had a PCL-R-mean lower than 16 or a PCL-R-CutOff of 20 points, and (c) the intelligence-test-mean and standard deviation was provided for both groups. In a few cases $(n=2)$ comparison studies with other psychopathy tests than the PCL-R were accepted due to comprehensible reasoning regarding the comparison, for example, test scores at least in the upper and lower quartiles of published norms for their respective age groups (Anderson \& Stanford, 2012). Since a lot of studies were excluded as a consequence, some of these studies were coded nevertheless (but separate from the other studies) to be included in a sensitivity analysis $(n=38)$. For each included comparison study a point biserial correlation was calculated in order to aggregate the results with the studies that reported Pearson correlations.

Subsequently, 170 studies were excluded: Some effect sizes were based on the same sample and published in different papers $(n=4)$, some effect sizes could not be aggregated to be used for the meta-analysis due to miscellaneous statistical and methodological reasons $(n=55)$, several studies made it impossible to calculate an effect size due to an inadequate group comparison regarding psychopathy $(n=75)$, some studies used inadequate D3- or intelligencetests $(n=24)$, some studies were "gray," unpublished literature $(n=8)$ or the studies were simply irrelevant for the research question $(n=4)$. Fortunately, some authors of the primary studies were contacted (see below) and were able to provide effect sizes (or raw data); these studies could be integrated into the analysis $(n=11)$. The final sample for the meta-analysis $(n=143)$ comprised 15 effect sizes for narcissism, 15 effect sizes for Machiavellianism, and 192 effect sizes for psychopathy (Pearson correlations: $k=137$; point biserial correlations: $k=55$ ). The information on the included studies and the reference list can be found in the dataset for this meta-analysis which is uploaded to the Open Science Framework and can be inspected by using the following link: https://osf.io/ws6kj/.

\section{Coding Studies}

A coding manual was used to extract the relevant information from the research reports by two independent coders. All discrepancies were inspected and resolved by the author of this study. When effects sizes (based on identical sample sizes) were only available for subscales of the tests, they were aggregated to a single effect size by simply determining the arithmetic mean of the effect sizes (only if effect sizes for every subscale were available). When studies reported more than one effect size based on different tests (e.g., one effect size for the Psychopathic Personality Inventory (PPI) and one for the PCL), then the effect size based on the PCL was preferred for P since the PCL is considered to be the gold standard test for P (Boduszek \& Debowska, 2016). The operationalizations of intelligence were categorized into three groups: (a) non-verbal intelligence (nvI; e.g., the Raven Progressive Matrices Test; Raven, 1981), for tests or subtests whose content was predominantly non-verbal, (b) verbal intelligence (nI; e.g., the Quick Word Test; Borgatta \& Corsini, 1964), for tests or subtests whose content was predominantly verbal, and (c) general intelligence (gI; e.g., the Wechsler Adult Intelligence Scale; Wechsler, 2012), for tests that incorporated at least two subtests with verbal and also non-verbal content. The complete coding rational can be found in the dataset for this meta-analysis.

\section{Method of Meta-Analysis}

The meta-analytic model used for the psychopathyintelligence relation is the random-effects model (RE model). For the intelligence-relation with $\mathrm{N}$ and $\mathrm{M}$, it appears to be more reasonable to use the fixed-effect model (FE) since the heterogeneity variance that plays an important role in the alternative RE model cannot be estimated with sufficient precision to avoid biased results if less than 30 studies are used to aggregate correlations in meta-analyses (Schulze, 2004). Additionally, it is difficult to argue that the available studies on $\mathrm{N}$ and $\mathrm{M}$ are a random sample from a well-defined universe of studies on that specific topic. Hence, the fixed-effect model was used because it is appropriate for the intended inference and does not suffer from statistical result distortions under the given circumstances in this meta-analysis. As a result, for the intelligencerelations to $\mathrm{N}$ and $\mathrm{M}$, the inference needs to be restricted to the set of studies included in the meta-analysis - while for P-intelligence inference about the average effect in the entire population of studies is possible. However, the results for both models are reported. For the aggregation of effect sizes, the minimum variance unbiased estimator as proposed by Olkin and Pratt (1958) was used. All computations were conducted with the package metafor 
(Viechtbauer, 2010) in $\mathrm{R}$ using the inverse sampling variance as weights.

\section{Collecting Raw Data}

Since the data from the primary studies only reported linear effect sizes it is not possible to draw any conclusions regarding possible non-linear relations. To examine those kinds of relations, it was indispensable to gain access to raw data. In August 2019, ninety studies from the systematic literature search were identified as potentially relevant. The focus was on the intelligence-psychopathy-relation since there were only a few studies for $\mathrm{N}$ and $\mathrm{M}$ regarding intelligence and the D3-tests in these studies on $\mathrm{N}$ and $\mathrm{M}$ were too heterogeneous - consequently, raw data from these studies could not have been pooled into a single data set.

The included studies had a sample size of at least $n=100$ with the PCL (or any of its variants) as the measure for psychopathy. 55 studies did not report any effect sizes but included relevant operationalizations, 35 studies included information regarding an effect size and had been included in the meta-analysis from the beginning. The author contacted the authors, provided information on the intentions, and asked for raw data regarding the P-intelligencerelation. It was specifically mentioned that nothing else but the PCL- and intelligence scores were needed and there were no intentions of using the data for anything else than calculating effect size. If the authors were unable to provide the relevant data, they were asked to report the Pearson correlation regarding the P-intelligence-relation (if it had not been stated in the paper already).

The author of this study contacted the authors via e-mail. A valid e-mail address for the 3 authors could not be found. 11 e-mail-accounts seemed to be inactive since mail delivery failure messages were received. Several authors responded to the message: 6 authors provided Pearson correlations and 7 authors sent the requested raw data. As a result, 11 additional studies could be included in the meta-analysis (see Figure 1). Some scale scores from raw data had to be transformed in order to aggregate them in one data set: (a) the PCL-Short-Version-scores (PCL-SV; Hart et al., 1995) were adjusted to the PCL-R-equivalent (possible values between 0 and 40) and (b) the intelligence scores from the Shipley Institute of Living Scale (SILS; Shipley, 1940) and the Leistungsprüfsystem 2 (LPS-2; Kreuzpointner et al., 2013) were transformed to IQ-values in accordance with norm values from Zachary et al. (1985) and the LPS-2manual. The included data sets stem from studies by Caldwell and Van Rybroek (2005), Copestake et al. (2013), Hale et al. (2004), Jumper et al. (2012), Kennealy et al. (2007), Köhler et al. (2016), and Snowden et al. (2004) and comprised a total sample size of $N=966$. Additional information regarding the studies can be retrieved from the dataset.

\section{Results}

The overall effect sizes are depicted in Table 1. All mean effect sizes are close to $\bar{r}=0$ with a tendency of negative effect sizes for P. Most relations are nonsignificant and none constitute a small effect size. The $k$ for $\mathrm{M}$ and $\mathrm{N}$ is considerably lower than the $k$ for P. The mean effect sizes resulting from the FE model or the RE model are very similar for almost all relationships. Note that there seem to be no meaningful differences between general, verbal and nonverbal intelligence.

The overall effect sizes at the facet level of psychopathy are depicted in Table 2 . The results show that the aspects of psychopathy that reflect an impulsive, haphazard and thrillseeking lifestyle, and a penchant for criminality (Factor 2, similar to secondary psychopathy) are negatively related to intelligence, whereas the interpersonal aspects of $\mathrm{P}$, e.g., a tendency to manipulate others with superficial charm and a feeling of grandiosity, (Facet 1) seem to be completely unrelated to intelligence.

Additionally, overall effect sizes were calculated with no distinction for general, verbal and nonverbal intelligence. If studies reported more than one effect size for different intelligence-branches that were based on the same sample, the effect size for general intelligence was chosen, otherwise the effect size for verbal intelligence. For psychopathy, there was a negative effect size of $\bar{r}=-.0751$ (CI [-.0999; $-.0502] ; k=152 ; N=34,253$; RE model). There were nonsignificant effects for Machiavellianism ( $\bar{r}=.0238$; CI [-.0216;.0691]; $k=15 ; N=1,901 ; \mathrm{FE}$ model) and narcissism $(\bar{r}=.0249 ; \mathrm{CI}[-.0133 ; .0630] ; k=13 ; N=2,634 ; \mathrm{FE}$ model $)$.

\section{Sensitivity Analysis}

In the course of a meta-analysis, many decisions have to be made by researchers that regularly influence the overall results. The exclusion of studies in the aforementioned systematic literature review might be considered too "rigorous" by some. An additional sensitivity analysis was conducted for a set of studies that had been excluded from the main analysis due to an inadequate group comparison regarding psychopathy (e.g., psychopathy-group-formation based on psychopathy test scores in that specific sample, see above). There was an average effect size of $\bar{r}=$ $-.1989(k=32 ; N=1,574$; RE model) for general intelligence and an average effect size of $\bar{r}=.1298(k=4 ; N=$ 199; FE model) for verbal intelligence. These findings seem to be slightly at odds with the results from the main analysis. Nevertheless, the inclusion would have been almost inconsequential and would lead to a weighted average effect size of $\bar{r}=-.0898$ (CI $[-.1220 ;-.0576] ; k=141$; $N=20,703$; RE model) for general intelligence - which would still be very close to zero. 


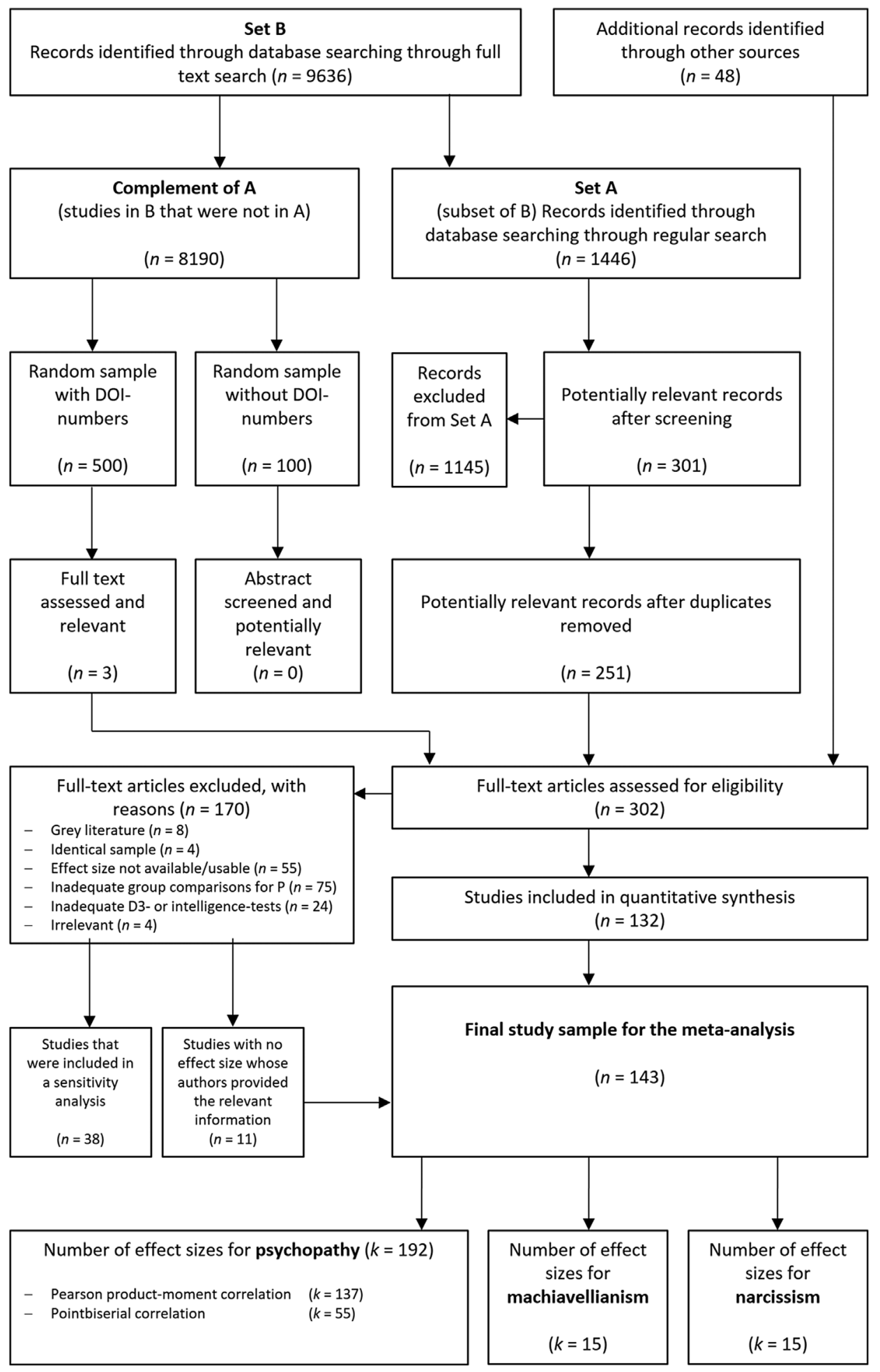

Figure 1. PRISMA flow chart for the systematic literature search.

\section{Moderator Analyses}

To quantify the heterogeneity of effect sizes $I^{2}$-values were calculated (Higgins \& Thompson, 2002) and are shown in Table 1 . The relations regarding psychopathy showed a substantial proportion of variance in observed effect sizes that is due to heterogeneity. The confidence intervals for $\mathrm{M}$ and $\mathrm{N}$ were relatively large due to the low number of studies available. Consequently, the $I^{2}$-values for $\mathrm{M}$ and $\mathrm{N}$ are not informative. 
Table 1. Overall relationships between the dark triad and intelligence

\begin{tabular}{lrrrccccc}
\hline Relation & \multicolumn{1}{c}{$\mathrm{k}$} & \multicolumn{1}{c}{$\mathrm{N}$} & \multicolumn{1}{c}{$\bar{r}_{\mathrm{FE}}$} & $95 \% \mathrm{Cl}(\mathrm{FE})$ & $\bar{r}_{\mathrm{RE}}$ & $95 \% \mathrm{Cl}(\mathrm{RE})$ & $1^{2}$ & $95 \% \mathrm{Cl}$ \\
\hline P-gl & 109 & 19,129 & -.0687 & {$[-.0827 ;-.0546]$} & -.0635 & {$[-.0933 ;-.0336]$} & 71.8581 & {$[60.9400 ; 79.7704]$} \\
P-vl & 47 & 16,749 & -.0996 & {$[-.1144 ;-.0847]$} & -.0784 & {$[-.1268 ;-.0299]$} & 88.6153 & {$[82.3225 ; 93.2156]$} \\
P-nvl & 36 & 10,743 & -.0671 & {$[-.0859 ;-.0484]$} & -.0203 & {$[-.0700 ; .0294]$} & 77.4833 & {$[55.3071 ; 86.3980]$} \\
M-gl & 2 & 337 & .0758 & {$[-.0315 ; .1830]$} & .0758 & {$[-.0315 ; .1830]$} & 0.0000 & {$[0.0000 ; 99.8407]$} \\
M-vl & 9 & 1,235 & .0047 & {$[-.0515 ; .0609]$} & .0047 & {$[-.0515 ; .0609]$} & 0.0702 & {$[0.0000 ; 86.2028]$} \\
M-nvl & 4 & 329 & .0422 & {$[-.0679 ; .1523]$} & .0422 & {$[-.0679 ; .1523]$} & 0.0000 & {$[0.0000 ; 86.2169]$} \\
N-gl & 3 & 168 & .0450 & {$[-.1106 ; .2005]$} & .0450 & {$[-.1106 ; .2005]$} & 0.0000 & {$[0.0000 ; 93.7032]$} \\
N-vl & 10 & 1,919 & -.0172 & {$[-.0620 ; .0275]$} & -.0229 & {$[-.0966 ; .0508]$} & 51.6779 & {$[0.0000 ; 90.6688]$} \\
N-nvl & 2 & 774 & .1120 & {$[.0423 ; .1818]$} & .0999 & {$[-.0039 ; .2038]$} & 44.9483 & {$[0.0000 ; 99.9459]$} \\
\hline
\end{tabular}

Notes. $g \mathrm{l}=$ general intelligence; $\mathrm{vl}=$ verbal intelligence; $\mathrm{nvl}=$ non-verbal intelligence; $\mathrm{k}=$ number of independent effect sizes; $N=$ aggregate sample size; $\bar{r}_{\mathrm{FE}}=$ overall effect size for a FE model; $\bar{r}_{\mathrm{RE}}=$ overall effect size for a RE model; $95 \% \mathrm{Cl}=95 \%$ confidence interval for $\rho$ (FE/RE model) or $I^{2} ; I^{2}=$ proportion of variance in observed effect sizes that is due to heterogeneity.

Table 2. Overall relationships between psychopathy facets and intelligence

\begin{tabular}{lccccc}
\hline Relation & $k$ & $\bar{r}_{\mathrm{FE}}$ & $95 \% \mathrm{Cl}(\mathrm{FE})$ & $\bar{r}_{\mathrm{RE}}$ & \multicolumn{1}{c}{$95 \% \mathrm{Cl}(\mathrm{RE})$} \\
\hline Facet 1 & 17 & -.0322 & {$[-.0618 ;-.0027]$} & -.0072 & {$[-.0713 ; .0570]$} \\
Facet 2 & 17 & -.1945 & {$[-.2228 ;-.1661]$} & -.1560 & {$[-.2308 ;-.0812]$} \\
Facet 3 & 17 & -.2343 & {$[-.2620 ;-.2065]$} & -.2020 & {$[-.2876 ;-.1163]$} \\
Facet 4 & 17 & -.2027 & {$[-.2312 ;-.1743]$} & -.1718 & {$[-.2293 ;-.1143]$} \\
Factor 1 & 38 & -.0674 & {$[-.0875 ;-.0474]$} & -.0327 & {$[-.0810 ; .0155]$} \\
Factor 2 & 38 & -.1664 & {$[-.1861 ;-.1468]$} & -.1432 & {$[-.1871 ;-.0992]$} \\
\hline
\end{tabular}

Notes. Facet 1 = Interpersonal Manipulation; Facet 2 = Callous Affect; Facet 3 = Erratic Lifestyle; Facet 4 = Anti-Social Behaviour; Factor 1 = Facet 1 and Facet 2; Factor 2 = Facet 3 and Facet 4. The Facet/Factor-structure is derived from common models of psychopathy (e.g., Hare, 2003). The Self-report Psychopathy Scale -Forth Edition (SRP-4; Paulhus et al., 2016) and the PCL-tests are based on this model.

A meta-regression was conducted with the following independent variables: (a) proportion of females in the sample, (b) mean age of the sample, (c) country in which the study was conducted, (d) sample type, (e) operationalization of intelligence, (f) operationalization of D3-constructs, and (g) sample mean of the D3-test compared to norm values. The possible categories of these variables are shown in the dataset (e.g., for the variable "subjects" there were the categories "offender," "kid," "community," "patient," and "student"). The moderator analysis was exploratory since there were no prior hypotheses regarding possible moderator effects.

Although there is no empirically or conceptually substantiated minimum $k$ to conduct meta-regression (Borenstein et al. 2009), its results should be interpreted with caution when the number of effect sizes is low. Therefore, the minimum $k$ to conduct a meta-regression in this study was set to ten studies. The overall results are presented in Table 3. Some of the predictors showed significant moderator effects. A consistent pattern of moderators does not exist, although the operationalizations of intelligence and $\mathrm{P}$ seem to be potential moderators for the psychopathy-intelligence relation. Note that the number of effect sizes dropped substantially in some cases (e.g., D3-level) since studies with no information regarding the moderator variables had to be excluded from the model. Consequently, subgroup analyses were inconclusive for most variables. A subgroup analysis for the psychopathy-intelligence-relation regarding P-tests showed the combined effect sizes for the PCL ( $\bar{r}=.0817, k=78, \mathrm{RE}$ model) were incomparable to other P-tests (that were not part of the PCL-test-"family," e.g., the PCL-SV) since the number of effect sizes that were based on other tests was very low $(k<6)$.

Note that it is impossible to attribute the moderator effects to specific moderators only due to their mutual confounding and their potential confounding with other known and/or unknown variables that might be the actual cause for the heterogeneity in observed effect sizes. For example, the PCL-test is commonly used only in forensic samples, whereas psychopathy-self-reports are predominantly used outside of prison. It is unknown if differences in effect sizes might exist due to the test itself or real differences in the samples. However, even if there are differences in effect sizes they appear to be very small.

Taken together, the results from the moderator analyses are limited and should be interpreted with great caution. 
Table 3. Moderator analysis

\begin{tabular}{lllll}
\hline Moderators & P-gl & $P$-vl & P-nvl & N-nvl \\
\hline F & $.0032(103)$ & $.0010(41)$ & $.0010(33)$ & $.0121(29)$ \\
Age & $.0523(84)$ & $.0899(26)$ & $.012(7)$ \\
Nationality & $.1714(105)$ & $.0980(46)$ & $.3818(36)$ & $.6907(5)$ \\
Sample type & $.1755(108)$ & $.2265(47)$ & $.0727(36)$ & $.5555(10)$ \\
I-test & $.0249(109)$ & $.4983(47)$ & $.4862(36)$ & $.3888(10)$ \\
D3-test & $.1894(109)$ & $.4854(47)$ & $.3909(36)$ & $.0344(12)$ \\
D3-level & $.0228(43)$ & $.1666(15)$ & $.2777(10)$ \\
\hline
\end{tabular}

Notes. The values in the cells show the amount of heterogeneity explained in the D3-intelligence-relation by the moderators $(Q$-statistic for test of moderators/total Q-statistic). "-" indicates no variance in the variable hence no moderator analysis was possible. Studies with NAs were omitted from model fitting. The $k$ that the moderator analysis is based on is in each case shown in parentheses. All outcomes are based on the fixed-effect model.

\section{File-Drawer-Analysis}

To test for a possible risk of publication bias, a fail-safe$\mathrm{N}$-analysis and tests for funnel-plot-asymmetry were conducted. The results can be seen in Table 4 . The failsafe-N by Rosenthal (1979) is only high $(>5 \times k+10)$ for the relations regarding $\mathrm{P}$. For $\mathrm{M}$ and $\mathrm{N}$ the fail-safe- $\mathrm{N}$ is zero (except for $\mathrm{N}$-nvI) since the overall meta-analytic effects were insignificant in the first place. Due to decreasing power of the tests to distinguish chance from real asymmetry, the tests for funnel-plot-asymmetry (Egger et al., 1997) were only conducted when at least ten studies were available as recommended by Sterne et al. (2008). None of tests, for funnel-plot-asymmetry showed significant results as can be seen in Table 4. Consequently, the author refrained from doing further analyses, for example, a trimand-fill-analysis (Duval \& Tweedie, 2000).

Although there was no reason to suspect a possible publication bias in the first place (almost no study in the metaanalysis had the D3-intelligence-relation as its main topic which would have indicated a lively discussed topic and therefore the risk of a publication bias), none of the results indicated a potential bias. However, the most convincing argument against a publication bias (in the sense of the withholding of studies with nonsignificant results) might be that almost all effect sizes in the analysis were very small and mostly nonsignificant. One can assume that there is indeed a negative relationship between psychopathy and intelligence with the notion that it is probably too small to be of any practical significance.

\section{Analysis of Raw Data}

Seven data sets were aggregated (total $N=966$ ). The PCLscores were rather high with $M=25.14(S D=8.07)$ and the average IQ was comparably low with $M=93.41(S D=$ 13.21). The isolated single data sets mostly showed correlations around $r=-1$. Surprisingly, the psychopathyintelligence-relation in the aggregated data set was $r=$ $-.322(p<.001,95 \%$ CI $[-.377 ;-.264]$, two-tailed test $)$
Table 4. Fail-safe- $\mathrm{N}$ analyses and Egger's regression test for funnelplot-asymmetry

\begin{tabular}{lrrccc}
\hline Relation & $\bar{r}_{\mathrm{FE}}$ & $\mathrm{FSN}_{\mathrm{RT}}$ & $5 \times k+10$ & $\mathrm{FSN}_{\mathrm{ORW}}$ & $p_{\text {Egger }}$ \\
\hline $\mathrm{P}-\mathrm{gl}$ & -.0687 & 1120 & 555 & 0 & .9086 \\
$\mathrm{P}-\mathrm{vl}$ & -.0996 & 824 & 245 & 0 & .1086 \\
$\mathrm{P}-\mathrm{nvl}$ & -.0671 & 25 & 190 & 0 & .6490 \\
$\mathrm{M}-\mathrm{gl}$ & .0758 & 0 & 20 & 0 & - \\
$\mathrm{M}-\mathrm{vl}$ & .0047 & 0 & 55 & 0 & - \\
$\mathrm{M}-\mathrm{nvl}$ & .0422 & 0 & 30 & 0 & - \\
$\mathrm{N}-\mathrm{gl}$ & .0450 & 0 & 25 & 0 & - \\
$\mathrm{N}-\mathrm{vl}$ & -.0172 & 0 & 60 & 0 & .2981 \\
$\mathrm{~N}-\mathrm{nvl}$ & .1120 & 1 & 20 & 0 & - \\
\hline
\end{tabular}

Notes. According to Rosenthal (1979), a publication bias seems unlikely if the fail-safe- $\mathrm{N}$ is higher than $5 \times k+10$. FSN $\mathrm{N}_{\mathrm{RT}}=$ Fail-safe- $\mathrm{N}$ by Rosenthal (1979) with target significance level $\alpha=.01 ; F S N_{\text {ORW }}=$ Fail-safe- $N$ by Orwin (1983), tested for $\bar{r} \leq-.1$ and $\bar{r} \geq .1$ ), $p_{\text {Egger }}=p$-value for Egger's regression test for funnel-plot-asymmetry (not applied for overall effect sizes based on less than 10 effect sizes, based on the RE model for P and the FE model for N).

which was considerably different from the meta-analytic results and might be due to range restriction in the isolated samples. Tests for linear and non-linear relationships were conducted: $R^{2}$ (with the PCL-value as the independent variable) was estimated for the optimal linear, quadratic and cubic regression models. The linear regression model explained $R^{2}=.104$ of the variance in IQ-values while the nonlinear regression models did not explain a meaningful additional amount of variance (quadratic: $R^{2}=.112$; cubic: $R^{2}=.113$ ). Therefore, linear models seem quite adequate to display the P-intelligence-relation.

\section{Discussion}

The meta-analysis showed that the D3 and intelligence are at most weakly related. Whereas the psychopathyintelligence-relation is negative, for $\mathrm{M}$ and $\mathrm{N}$ there seems to be no relation at all. It should be noted that the study sample for $\mathrm{M}$ and $\mathrm{N}$ is considerably lower compared to $\mathrm{P}$. 
Two of three expectations were corroborated. Whereas M and $\mathrm{N}$ were (as expected) not related to cognitive abilities, the relation between psychopathy and intelligence was significant but very small. The cause for the effect might be the overlap between $P$ and criminality: the latter has shown to be negatively related to intelligence. This becomes particularly evident considering the small negative relation between intelligence and the P-Factor 2 (the aspect of psychopathy that comprises norm-violating behavior). Since criminality is part of many P-test-items, it would be inadequate to interpret this overlap as confounding. Furthermore, intelligence is negatively related to impulsivity (Schweizer, 2002; Vigil-Coleț \& Morales-Vives, 2005) and aggression (Ackerman \& Heggestad, 1997) - two conceptual features of Factor 2 psychopathy. Alternatively, the negative P-intelligence-relation might be due to range restriction in the primary studies and might disappear in the course of a secondary analysis of all raw data - yet the analysis of raw data mentioned above suggests the opposite. Nevertheless, the results indicate that D3-individuals do not have superior cognitive abilities that might enable them to show complex manipulative behavior. On the other hand, they do not seem to have relevant cognitive deficits as well. If one assumes that D3-individuals can indeed be more successful in some contexts than others (an assumption that should be scrutinized in the first place), this analysis demonstrates that this possible success is not a consequence of high cognitive abilities.

Surprisingly, the reanalysis of the raw data showed a moderate negative relation with intelligence: it is unclear if the study sample coincidently showed a moderate effect or if the meta-analytic results might have to be reinterpreted. A reanalysis of the original data from the primary studies might have shown similar results due to an underestimation of effect sizes due to range restriction in the isolated studies. But note that an overestimation of the effect in this meta-analysis is also possible due to range restriction. On the other hand, for example, Watts et al. (2016) found similar results as in this meta-analysis regarding P-intelligence and did correct for range restriction using a formula for correcting correlation estimates by Hunter and Schmidt (1990), which did not alter their overall results. However, the results from a P-gI-meta-analysis with $k>100$ might be more credible than the reanalysis of only 7 datasets. The reanalysis of raw data did not raise any reason to further inspect the D3-relations to intelligence in regards to non-linear relationships.

\section{Limitations of the Meta-Analysis}

A few limitations of this meta-analysis should be considered: First, the combined effect sizes remained heterogeneous even after moderators had been taken into account. As a result, the reported overall effects may be quite different in subpopulations not under investigation in the present study. Second, the number of studies for $\mathrm{M}$ and $\mathrm{N}$ was very small, so that the inference had to be restricted to the types of studies under investigation and cannot be further generalized due to the use of the FE model. Third, the selection of tests for $\mathrm{M}$ and $\mathrm{N}$ that were used in the primary studies was narrow - which also made possible subscale-analyses for $\mathrm{M}$ and $\mathrm{N}$ impossible. This does not apply for $\mathrm{P}$ and most of the studies used the PCL (which is considered the "gold standard"-measure for psychopathy). Forth, a more fine-grained analysis of intelligence subdimensions on the basis of an overarching model of intelligence - preferably the Cattell-Horn-Carroll theory (Carroll, 1993) - would have been desirable. Since the number of effect sizes per effectsize-category (e.g., P-gI) would have dropped substantially, a rather rough separation into verbal and non-verbal was the pragmatic consequence. Lastly, no gray literature was included in this analysis: Since there was no specific search for unpublished studies on the research question, a substantial body of literature might have been missed - nevertheless, the gray studies that were identified did not differ in methodology nor the reported effect size. Consequently, there was no reason to include them.

\section{Concluding Remarks}

The results relativize the assumption that the dark triad of personality is related to special abilities and is therefore an adaptive set of traits. None of the three traits is positively related to intelligence - D3-individuals do not have special cognitive abilities that fuel the effectiveness of their manipulative endeavors. For some readers, these results might raise a question: If D3-individuals are not smarter than others, how are they capable to effectively manipulate others? The author does not regard this as a valid question, since it implies that D3-individuals are indeed more successful in some areas of activities. There is no convincing empirical evidence that shows that D3-individuals are indeed "getting ahead." A plausible requirement for high cognitive abilities to show certain behavior (e.g., successful manipulations) does not constitute the actual presence of such high abilities. Although the dark triad and intelligence are unrelated, it has yet to be explored if there are interaction effects for D3-intelligence in regards to meaningful external criteria: At least for the psychopathycriminality-relation intelligence is often discussed as a potential moderator (Hall \& Benning, 2006; Heilbrun, 1982; Vitacco et al., 2008). Taken together, a meaningful D3-intelligence-relation was not expected and none was found. 


\section{References}

Ackerman, P. L., \& Heggestad, E. D. (1997). Intelligence, personality, and interests: Evidence for overlapping traits. Psychological Bulletin, 121(2), 219-245. https://doi.org/10.1037/0033-2909. 121.2.219

Anderson, N. E., \& Stanford, M. S. (2012). Demonstrating emotional processing differences in psychopathy using affective ERP modulation. Psychophysiology, 49(6), 792-806. https://doi. org/10.1111/j.1469-8986.2012.01369.x

Babiak, P., \& Hare, R. D. (2006). Snakes in suits: When psychopaths go to work. Regan Books.

Babiak, P., Neumann, C. S., \& Hare, R. D. (2010). Corporate psychopathy: Talking the walk. Behavioral Sciences \& the Law, 28(2), 174-193. https://doi.org/10.1002/bsl.925

Back, M. D., Schmukle, S. C., \& Egloff, B. (2010). Why are narcissists so charming at first sight? Decoding the narcissism-popularity link at zero acquaintance. Journal of Personality and Social Psychology, 98(1), 132-145. https://doi.org/10.1037/a0016338

Bartels, J. M., Ryan, J. J., Urban, L. S., \& Glass, L. A. (2010). Correlations between estimates of state $\mathrm{IQ}$ and $\mathrm{FBl}$ crime statistics. Personality and Individual Differences, 48(5), 579583. https://doi.org/10.1016/j.paid.2009.12.010

Bereczkei, T. (2018). Machiavellian intelligence hypothesis revisited: What evolved cognitive and social skills may underlie human manipulation. Evolutionary Behavioral Sciences, 12(1), 32-51. https://doi.org/10.1037/ebs0000096

Boduszek, D., \& Debowska, A. (2016). Critical evaluation of psychopathy measurement (PCL-R and SRP-III/SF) and recommendations for future research. Journal of Criminal Justice, 44, 1-12. https://doi.org/10.1016/j.jcrimjus.2015.11.004

Borenstein, M., Hedges, L. V., Higgins, J. P., \& Rothstein, H. R. (2009). Introduction to meta-analysis. Wiley.

Borgatta, E. F., \& Corsini, R. J. (1964). Quick Word Test Manual. Harcourt, Brace \& World.

Caldwell, M. F., \& Van Rybroek, G. J. (2005). Reducing violence in serious juvenile offenders using intensive treatment. International Journal of Law and Psychiatry, 28(6), 622-636. https:// doi.org/10.1016/j.ijlp.2004.07.001

Carroll, J. B. (1993). Human cognitive abilities: A survey of factoranalytic studies. Cambridge University Press.

Christie, R., \& Geis, F. (1970). Studies in Machiavellianism. Academic Press.

Cleckley, H. (1941). The mask of sanity. Mosby.

Conzelmann, K., Weis, S., \& Süß, H. (2013). New findings about social intelligence: Development and application of the Magdeburg Test of Social Intelligence (MTSI). Journal of Individual Differences, 34(3), 119-137. https://doi.org/10.1027/1614$0001 / a 000106$

Copestake, S., Gray, N. S., \& Snowden, R. J. (2013). Emotional intelligence and psychopathy: A comparison of trait and ability measures. Emotion, 13(4), 691-702. https://doi.org/10.1037/ a0031746

De Ribera, O. S., Kavish, N., \& Boutwell, B. (2017). On the relationship between psychopathy and general intelligence: $A$ meta-analytic review. bioRxiv. https://doi.org/10.1101/100693

Duval, S., \& Tweedie, R. (2000). Trim and fill: A simple funnel-plotbased method of testing and adjusting for publication bias in meta-analysis. Biometrics, 56(2), 455-463. https://doi.org/ 10.1111/j.0006-341X.2000.00455.X

Egger, M., Smith, G. D., Schneider, M., \& Minder, C. (1997). Bias in meta-analysis detected by a simple, graphical test. British Medical Journal, 315, 629-634. https://doi.org/10.1136/bmj. 315.7109.629
Fowles, D. C., \& Dindo, L. (2006). A dual-deficit model of psychopathy. In C. J. Patrick (Ed.), Handbook of psychopathy. Guilford Press.

Furnham, A. (2010). The elephant in the boardroom: The causes of leadership derailment. Springer.

Furnham, A., Moutafi, J., \& Chamorro-Premuzic, T. (2005). Personality and intelligence: Gender, the Big Five, selfestimated and psychometric intelligence. International Journal of Selection and Assessment, 13(1), 11-24. https://doi.org/ 10.1111/j.0965-075X.2005.00296.x

Furnham, A., Richards, S. C., \& Paulhus, D. L. (2013). The dark triad of personality: A 10 year review. Social and Personality Psychology Compass, 7(3), 199-216. https://doi.org/10.1111/ spc3.12018

Gabriel, M. T., Critelli, J.W., \& Ee, J. S. (1994). Narcissistic illusions in self-evaluations of intelligence and attractiveness. Journal of Personality, 62(1), 143-155. https://doi.org/10.1111/ j.1467-6494.1994.tb00798.x

Gendreau, P., Little, T., \& Goggin, C. (1996). A meta-analysis of the predictors of adult offender recidivism: What works!. Criminology, 34(4), 575-608. https://doi.org/10.1111/j.1745-9125.1996. tb01220.x

Grijalva, E., Harms, P. D., Newman, D. A., Gaddis, B. H., \& Fraley, R. C. (2015). Narcissism and leadership: A meta-analytic review of linear and nonlinear relationships. Personnel Psychology, 68(1), 1-47. https://doi.org/10.1111/peps.12072

Hale, L. R., Goldstein, D. S., Abramowitz, C. S., Calamari, J. E., \& Kosson, D. S. (2004). Psychopathy is related to negative affectivity but not to anxiety sensitivity. Behaviour Research and Therapy, 42(6), 697-710. https://doi.org/10.1016/S00057967(03)00192-X

Hall, J. R., \& Benning, S. D. (2006). The "successful" psychopath Adaptive and subclinical manifestations of psychopathy in the general population. In C. J. Patrick (Ed.), Handbook of psychopathy (pp. 459-478). Guilford Press.

Hare, R. D. (1999). Without conscience: The disturbing world of the psychopaths among us. Guilford Press.

Hare, R. D. (2003). Manual for the Hare Psychopathy Checklist Revised. Multi Health Systems.

Hart, S. D., Cox, D. N., \& Hare, R. D. (1995). Manual for the Hare Psychopathy Checklist - Revised: Screening Version (PCL:SV). Multi-Health Systems.

Heilbrun, A. B. (1982). Cognitive models of criminal violence based upon intelligence and psychopathy levels. Journal of Consulting and Clinical Psychology, 50(4), 546-557. https://doi.org/ 10.1037/0022-006X.50.4.546

Hiatt, K. D., \& Newman, J. P. (2006). Understanding psychopathy: The cognitive side. In C. J. Patrick (Ed.), Handbook of psychopathy (pp. 334-352). Guilford Press.

Higgins, J., \& Thompson, S. G. (2002). Quantifying heterogeneity in a meta-analysis. Statistics in Medicine, 21(11), 1539-1558. https://doi.org/10.1002/sim.1186

Hodson, G., Book, A., Visser, B. A., Volk, A. A., Ashton, M. C., \& Lee, K. (2018). Is the dark triad common factor distinct from low honesty-humility? Journal of Research in Personality, 73, 123-129. https://doi.org/10.1016/j.jrp.2017.11.012

Hunter, J. E., \& Schmidt, F. L. (1990). Dichotomization of continuous variables: The implications for meta-analysis. Journal of Applied Psychology, 75(3), 334-349. https://doi.org/10.1037/ 0021-9010.75.3.334

Jauk, E., Neubauer, A. C., Mairunteregger, T., Pemp, S., Sieber, K. P., \& Rauthmann, J. F. (2016). How alluring are dark personalities? The dark triad and attractiveness in speed dating. European Journal of Personality, 30(2), 125-138. https://doi.org/10.1002/per.2040 
Johansson, P., \& Kerr, M. (2005). Psychopathy and intelligence: A second look. Journal of Personality Disorders, 19(4), 357-369. https://doi.org/10.1521/pedi.2005.19.4.357

Jonason, P. K., \& Webster, G. D. (2012). A protean approach to social influence: Dark triad personalities and social influence tactics. Personality and Individual Differences, 52(4), 521-526. https://doi.org/10.1016/j.paid.2011.11.023

Jonason, P. K., Webster, G. D., Schmitt, D. P., Li, N. P., \& Crysel, L. (2012). The antihero in popular culture: Life history theory and the dark triad personality traits. Review of General Psychology, 16(2), 192-199. https://doi.org/10.1037/a0027914

Jones, D. N., \& Paulhus, D. L. (2009). Machiavellianism. In M. R. Leary \& R. H. Hoyle (Eds.), Handbook of individual differences in social behavior (pp. 93-108). Guilford Press.

Jones, D. N., \& Paulhus, D. L. (2011). Differentiating the dark triad within the interpersonal circumplex. In L. M. Horowitz \& S. Strack (Eds.), Handbook of interpersonal psychology: Theory, research, assessment, and therapeutic interventions (pp. 249-267). Wiley.

Jumper, S., Babula, M., \& Casbon, T. (2012). Diagnostic profiles of civilly committed sexual offenders in Illinois and other reporting jurisdictions: What we know so far. International journal of offender therapy and comparative criminology, 56(6), 838-855. https://doi.org/10.1177/0306624X11415509

Kennealy, P. J., Hicks, B. M., \& Patrick, C. J. (2007). Validity of factors of the Psychopathy Checklist-Revised in female prisoners: Discriminant relations with antisocial behavior, substance abuse, and personality. Assessment, 14(4), 323-340. https://doi. org/10.1177/1073191107305882

Köhler, D., Neubert, L., Hinrichs, G., \& Huchzermeier, C. (2016). Die Rückfälligkeit von Inhaftierten des Jugendstrafvollzuges: Die Vorhersagekraft von Psychischen Störungen, Persönlichkeit, Intelligenz und Therapiemotivation [The recidivism of inmates in the juvenile prison system: The predictive power of mental disorders, personality, intelligence and therapy motivation]. RPsych Rechtspsychologie, 2(4), 448-469. https://doi.org/ 10.5771/2365-1083-2016-4-448

Kreuzpointner, L., Lukesch, H., \& Horn, W. (2013). Leistungsprüfsystem 2. LPS-2 Manual [Performance Testing System 2 Manual]. Hogrefe.

Leary, T., \& Ashman, J. (2018). Narcissistic leadership: Important considerations and practical implications. International Leadership Journal, 10, 62-74.

Lee, K., \& Ashton, M. C. (2013). The H factor of personality: Why some people are manipulative, self-entitled, materialistic, and exploitive - and why it matters for everyone. Wilfrid Laurier University Press.

Lilienfeld, S. O., Watts, A. L., \& Smith, S. F. (2015). Successful psychopathy: A scientific status report. Current Directions in Psychological Science, 24(4), 298-303. https://doi.org/10.1177/ 0963721415580297

Mayer, J. D., Caruso, D. R., \& Salovey, P. (2016). The ability model of emotional intelligence: Principles and updates. Emotion Review, 8(4), 290-300. https://doi.org/10.1177/1754073916639667

McHoskey, J. W., Worzel, W., \& Szyarto, C. (1998). Machiavellianism and psychopathy. Journal of Personality and Social Psychology, 74(1), 192-210. https://doi.org/10.1037/0022-3514.74.1.192

Megías, A., Gómez-Leal, R., Gutiérrez-Cobo, M. J., Cabello, R., \& Fernández-Berrocal, P. (2018). The relationship between trait psychopathy and emotional intelligence: A meta-analytic review. Neuroscience \& Biobehavioral Reviews, 84, 198-203. https://doi.org/10.1016/j.neubiorev.2017.12.003

Miao, C., Humphrey, R. H., Qian, S., \& Pollack, J. M. (2019). The relationship between emotional intelligence and the dark triad personality traits: A meta-analytic review. Journal of Research in Personality, 78, 189-197. https://doi.org/10.1016/j.jrp.2018. 12.004
Michels, M. (2020). General intelligence and the Dark Triad: A metaanalysis [Unpublished raw data]. OSF. https://osf.io/ws6kj/

Moher, D., Liberati, A., Tetzlaff, J., \& Altman, D. G., The PRISMA Group. (2009). Preferred reporting items for systematic reviews and meta-analyses: The PRISMA statement. PLoS Medicine, 6(7), Article e1000097. https://doi.org/10.1371/journal.pmed. 1000097

Moshagen, M., Hilbig, B. E., \& Zettler, I. (2018). The dark core of personality. Psychological Review. Advance online publication. https://doi.org/10.1037/rev0000111

Muris, P., Merckelbach, H., Otgaar, H., \& Meijer, E. (2017). The malevolent side of human nature: A meta-analysis and critical review of the literature on the dark triad (narcissism, Machiavellianism, and psychopathy). Perspectives on Psychological Science, 12(2), 183-204. https://doi.org/10.1177/1745691616666070

Nagler, U. K., Reiter, K. J., Furtner, M. R., \& Rauthmann, J. F. (2014). Is there a "dark intelligence"? Emotional intelligence is used by dark personalities to emotionally manipulate others. Personality and Individual Differences, 65, 47-52. https://doi. org/10.1016/j.paid.2014.01.025

O'Boyle, E. H., Forsyth, D., Banks, G. C., \& Story, P. A. (2013). A meta-analytic review of the dark triad - intelligence connection. Journal of Research in Personality, 47(6), 789-794. https://doi.org/10.1016/j.jrp.2013.08.001

O'Boyle, E. H., Forsyth, D. R., Banks, G. C., Story, P. A., \& White, C. D. (2015). A meta-analytic test of redundancy and relative importance of the dark triad and five-factor model of personality. Journal of Personality, 83(6), 644-664. https://doi.org/ 10.1111/jopy.12126

Oh, I. S., Le, H., Whitman, D. S., Kim, K., Yoo, T. Y., Hwang, J. O., \& Kim, C. S. (2014). The incremental validity of honesty-humility over cognitive ability and the big five personality traits. Human Performance, 27(3), 206-224. https://doi.org/10.1080/08959285. 2014.913594

Olkin, I., \& Pratt, J.W. (1958). Unbiased estimation of certain correlation coefficients. Annals of Mathematical Statistics, 29, 201-211.

Orwin, R. G. (1983). A fail-safe $N$ for effect size in meta-analysis. Journal of Educational Statistics, 8(2), 157-159. https://doi. org/10.3102/10769986008002157

Paulhus, D. L. (1998). Interpersonal and intrapsychic adaptiveness of trait self-enhancement: A mixed blessing? Journal of Personality and Social Psychology, 74(5), 1197-1208. https:// doi.org/10.1037//0022-3514.74.5.1197

Paulhus, D. L. (2014). Toward a taxonomy of dark personalities. Current Directions in Psychological Science, 23(6), 421-426. https://doi.org/10.1177/0963721414547737

Paulhus, D. L., Neumann, C. S., \& Hare, R. D. (2016). Manual for the Self-Report Psychopathy Scale (4th ed.). Multi Health Systems.

Paulhus, D. L., \& Williams, K. M. (2002). The dark triad of personality: Narcissism, machiavellianism, and psychopathy. Journal of Research in Personality, 36(6), 556-563. https://doi. org/10.1016/S0092-6566(02)00505-6

Porter, S., ten Brinke, L., \& Wilson, K. (2009). Crime profiles and conditional release performance of psychopathic and nonpsychopathic sexual offenders. Legal and Criminological Psychology, 14(1), 109-118. https://doi.org/10.1348/135532508X284310

Raskin, R., \& Hall, C. S. (1981). The narcissistic personality inventory: Alternative form reliability and further evidence of construct validity. Journal of Personality Assessment, 45(2), 159-162. https://doi.org/10.1207/s15327752jpa4502_10

Raven, J. (1981). Manual for raven's progressive matrices and vocabulary scales. Research supplement no. 1: the 1979 British standardisation of the standard progressive matrices and mill hill vocabulary scales, together with comparative data from earlier 
studies in the UK, US, Canada, Germany and Ireland. Oxford University Press \& The Psychological Corporation.

Rosenthal, R. (1979). The file drawer problem and tolerance for null results. Psychological Bulletin, 86(3), 638-641. https://doi. org/10.1037/0033-2909.86.3.638

Salekin, R. T., Neumann, C. S., Leistico, A. M. R., \& Zalot, A. A. (2004). Psychopathy in youth and intelligence: An investigation of Cleckley's hypothesis. Journal of Clinical Child and Adolescent Psychology, 33(4), 31-742. https://doi.org/10.1207/ s15374424jccp3304_8

Schmidt, F. L., \& Hunter, J. E. (1998). The validity and utility of selection methods in personnel psychology: Practical and theoretical implications of 85 years of research findings. Psychological Bulletin, 124(2), 262-274. https://doi.org/ 10.1037/0033-2909.124.2.262

Schulze, R. (2004). Meta-analysis: A comparison of approaches. Hogrefe \& Huber.

Schweizer, K. (2002). Does impulsivity influence performance in reasoning? Personality and Individual Differences, 33(7), 1031-1043. https://doi.org/10.1016/S0191-8869(01)00209-4

Sharratt, K., Boduszek, D., \& Retzler, C. (2019). Clarifying the relationship between psychopathy and intelligence using four dimensions of the WASI-II. Deviant Behavior, 41(5), 619-627. https://doi.org/10.1080/01639625.2019.1582968

Shipley, W. C. (1940). A self-administering scale for measuring intellectual impairment and deterioration. The Journal of Psychology, 9, 371-377.

Simonton, D. K. (1986). Presidential personality: Biographical use of the gough adjective check list. Journal of Personality and Social Psychology, 51(1), 149-160. https://doi.org/10.1037/ 0022-3514.51.1.149

Snowden, R., Gray, N., Smith, J., Morris, M., \& MacCulloch, M. (2004). Implicit affective associations to violence in psychopathic murderers. Journal of Forensic Psychiatry \& Psychology, 15(4), 620-641. https://doi.org/10.1080/14789940412331313377

Sternberg, R. J. (1997). The concept of intelligence and its role in lifelong learning and success. American Psychologist, 52(10), 1030-1037. https://doi.org/10.1037/0003-066X.52.10. 1030

Sterne, J. A., Egger, M., \& Moher, D. (2008). Addressing reporting biases. In J. P. Higgins \& S. Green (Eds.), Cochrane handbook for systematic reviews of interventions: Cochrane book series (pp. 297-333). Wiley.

Strenze, T. (2007). Intelligence and socioeconomic success: A meta-analytic review of longitudinal research. Intelligence, 35(5), 401-426. https://doi.org/10.1016/j.intell.2006.09.004

Vigil-Colet, A., \& Morales-Vives, F. (2005). How impulsivity is related to intelligence and academic achievement. The Spanish Journal of Psychology, 8(2), 199-204. https://doi.org/10.1017/ S1138741600005072

Vitacco, M. J., Neumann, C. S., \& Wodushek, T. (2008). Differential relationships between the dimensions of psychopathy and intelligence: Replication with adult jail inmates. Criminal Justice and Behavior, 35(1), 48-55. https://doi.org/10.1177/ 0093854807309806

Vize, C. E., Lynam, D. R., Collison, K. L., \& Miller, J. D. (2018). Differences among dark triad components: A meta-analytic investigation. Personality Disorders: Theory, Research, and Treatment, 9(2), 101-111. https://doi.org/10.1037/per0000222

Viechtbauer, W. (2010). Conducting meta-analyses in R with the metafor package. Journal of Statistical Software, 36(3), 1-48. https://doi.org/10.18637/jss.v036.i03

Watts, A. L., Lilienfeld, S. O., Smith, S. F., Miller, J. D., Campbell, W. K., Waldman, I. D., Rubenzer, S. J., \& Faschingbauer, T. J. (2013). The double-edged sword of grandiose narcissism:
Implications for successful and unsuccessful leadership among US Presidents. Psychological Science, 24(12), 23792389. https://doi.org/10.1177/0956797613491970

Watts, A. L., Salekin, R. T., Harrison, N., Clark, A., Waldman, I. D., Vitacco, M. J., \& Lilienfeld, S. O. (2016). Psychopathy: Relations with three conceptions of intelligence. Personality Disorders: Theory, Research, and Treatment, 7(3), 269-279. https://doi. org/10.1037/per0000183

Wechsler, D. (2012). Wechsler Adult Intelligence Scale (4th ed.). Psychological Corporation.

Whiten, A., \& Byrne, R. W. (1997). Machiavellian Intelligence II: Extensions and evaluations (Vol. 2). Cambridge University Press.

Wilson, D. S., Near, D. C., \& Miller, R. R. (1998). Individual differences in Machiavellianism as a mix of cooperative and exploitative strategies. Evolution and Human Behavior, 19(3), 203-212. https://doi.org/10.1016/S1090-5138(98)00011-7

Wright, G. R., Berry, C. J., Catmur, C., \& Bird, G. (2015). Good liars are neither "dark" nor self-deceptive. PLoS One, 10, Article e0127315. https://doi.org/10.1371/journal.pone.0127315

Zettler, I., \& Solga, M. (2013). Not enough of a 'dark' trait? Linking machiavellianism to job performance. European Journal of Personality, 27(6), 545-554. https://doi.org/10.1002/per.1912

Zachary, R. A., Paulson, M. J., \& Gorsuch, R. L. (1985). Estimating WAIS IQ from the Shipley Institute of Living Scale using continuously adjusted age norms. Journal of Clinical Psychology, 41(6), 820-831. https://doi.org/10.1002/1097-4679 (198511)41:6<820::AID-JCLP2270410616>3.0.CO;2-X

Zajenkowski, M., \& Dufner, M. (2020). Why do narcissists care so much about intelligence? Current Directions in Psychological Science, 29(3), 261-266. https://doi.org/10.1177/ 0963721420917152

\section{History}

Received October 12, 2020

Revision received May 6, 2021

Accepted May 21, 2021

Published online October 14, 2021

\section{Acknowledgments}

The author would like to thank the authors who provided the raw data for this analysis for their help and trust.

\section{Conflict of Interest}

The author has no conflict of interest.

\section{Open Data}

The information on the included studies and the reference list can be found in the dataset for this meta-analysis which is uploaded to the Open Science Framework and can be inspected by using the following link: https://osf.io/ws6kj/

\section{Funding}

The author did not receive funding for this particular research paper. Open access publication enabled by the University of Wuppertal.

\section{Moritz Michels}

Institute of Psychology

University of Wuppertal

Gaußstraße 20

42119 Wuppertal

Germany

moritz-michels@gmx.net 